\title{
PENENTUAN STATUS PEMANFAATAN IKAN TERI (Stolephorus sp) DI PERAIRAN SELAT LALANG KECAMATAN SUNGAI APIT KABUPATEN SIAK PROVINSI RIAU
}

\author{
Zulkarnaini $^{1}$, Hazmi Arief ${ }^{1}$, Zuriati Murni ${ }^{2}$ \\ ${ }^{1}$ Dosen Program Studi Agrobisnis Perikanan Fakultas Perikanan dan Kelautan UNRI \\ ${ }^{2}$ Mahasiwa Program Studi Agrobisnis Fakultas Perikanan dan Kelautan UNRI \\ gmail : zuriati.murni2133@ student.unri.ac.id
}

\begin{abstract}
ABSTRAK
Ikan Teri (Stolephorus sp) merupakan salah satu sumberdaya ikan yang bernilai ekonomi penting dengan tingkat produksi yang meningkat di perairan selat Lalang. Meskipun sumberdaya ikan sebagai sumberdaya alam yang bersifat open access jika tidak dikelola dengan baik, maka pengelolaan sumberdaya perikanan tidak optimal dan berkelanjutan. Salah satu analisis yang digunakan untuk pengelolaan sumberdaya ikan ialah dengan menggunakan potensi maksimum lestari dari model Produksi Surplus Walter-Hilborn. Penelitian dilakukan di desa-desa yang menjadi penghasil sumberdaya ikan Teri di Kecamatan Sungai Apit Kabupaten Siak Provinsi Riau. Data yang digunakan adalah data hasil tangkapan dan upaya tangkap ikan teri yang diperoleh dari Dinas Perikanan dan Peternakan Kabupaten Siak. Berdasarkan hasil analisis diperoleh bahwa status pemanfaatan ikan Teri ialah $70 \%$, dengan tingkat pengusahaan sebesar 41\%. Ini menunjukkan bahwa, ikan Teri di Perairan Selat Lalang berada dalam status moderately exploited.
\end{abstract}

Kata kunci : Status Pemanfaatan, Ikan teri, Walter-Hilborn model, Selat Lalang

\section{ABSTRACT}

The anchovies (stolephorus sp) need to be well managed, for although they are open access resources if not properly managed, fisheries resources are poorly maintained and sustainable. One approach to managing fish resources is with a production surplus model. As for the data method used is a secondary data analysis method, which USES a production surplus model. Analysis was done to acquire the best production model that could provide information on the extent of use and the completion of anchovies. Data from catch and catch fish were obtained from the registry service of siak district fisheries and livestock. Analysis suggests that the best surplus production model, which is used to assess the potential for anchovies, is the walter-hilborn model. The level of utilization for 2020 is 70 percent, with a $41 \%$ reduction rate. It shows that, anchovies in the lalang strait in the state of moderately expoited.

Keywords : Lalang Strait, Anchovy, Walter-Hilborn Equation, fish catch exploitation status

\section{PENDAHULUAN}

Ikan teri (Stolephorus sp) tergolong sumberdaya perikanan pelagis dan merupakan salah satu komoditi ikan yang mengalami peningkatan produksi di perairan Selat Lalang. Produksi ikan teri pada tahun 2012-2020 yakni dari 68,86 ton mencapai 173,15 ton per 
tahunnya (Dinas Perikanan dan Peternakan, 2021).

Penangkapan ikan teri di perairan Selat Lalang telah berlangsung cukup lama, dengan tingkat produksi yang dominan dibandingkan jenis ikan lainnya. Kondisi meningkatnya produksi ikan Teri diduga sebagai akibat peningkatan jumlah alat tangkap ikan Teri yang cukup signifikan yaitu 27 unit di tahun 2012 menjadi 47 unit di tahun 2020. Peningkatan jumlah alat tangkap ini menyebabkan tingginya produksi ikan Teri yang mencapai 173,15 Ton/tahun. (Dinas Perikanan dan Peternakan Kabupaten Siak, 2020)

Mengingat pemanfaatan sumberdaya ikan bersifat open access. namun perlu adanya kehati-hatian dalam pemanfaatannya untuk menjamin ketersediaan stok sumberdaya ikan di alam. Pemanfaatan sumberdaya ikan yang berlebihan akan mengancam kelestariannya.

Dengan mengetahui status tingkat pemanfaatan sumberdaya ikan teri, dapat dijadikan acuan untuk pemanfaatan sumberdaya ikan teri yang optimal dalam jangka panjang namun tetap menjaga kelestarian. Penelitian ini bertujuan untuk menentukan tingkat pemanfaatan serta tingkat pengusahaan ikan teri di perairan Selat Lalang.

\section{METODOLOGI PENELITIAN}

Data yang dikumpulkan menggunakan metode survei dan dokumentasi. Jenis data yang digunakan adalah data primer dan data sekunder. Metode survei dilakukan untuk memperoleh data primer yang terdiri dari produksi ikan Teri, jumlah upaya penangkapan dan metode dokumentasi dilakukan untuk memperoleh data sekunder yang terdiri dari data time series selama 9 tahun
(2012-2020) dari Dinas Perikanan dan Peternakan Kabupaten Siak.

\section{Metode Analisis Data}

Analisis upaya penangkapan optimum $\left(f_{\text {opt }}\right)$ dan MSY dihitung dengan menggunakan persamaan Walter-Hilborn.

Model Walter dan Hilborn dapat dijelaskan pada persamaan berikut :

$$
x_{t+i}=x_{t}+r x_{t}\left(1-\frac{x_{t}}{K}\right)-\mathrm{h}_{\mathrm{t}}
$$

Model Walter dan Hilborn menggunakan versi diskrit model biologi sedangkan Schaefer tidak. Estimasi parameter biologi dengan menggunakan metode estimasi dinamis atau dikenal dengan metode regresi relatif lebih mudah karena dapat mengestimasi parameter biologi langsung dari persamaannya (Walter dan Hilborn 1992). Prosedur estimasi parameter biologi dengan menggunakan Walter dan Hilborn adalah :

$$
\frac{U_{t+1}}{q}=\frac{U_{t}}{q}+\frac{r U_{t}}{q}\left(1-\frac{U_{t}}{K q}\right)-U_{t} E_{t}
$$

Dengan memindahkan Ut/q ke sebelah kiri tanda sama dengan dan mengalikan semua sisi dengan $\mathrm{q} / \mathrm{Ut}$ Secara umum bentuk regresi model surplus produksi Walter dan Hilborn dapat ditulis sebagai berikut :

$$
\frac{U_{t+1}}{U_{t}}-1=r-\frac{r}{K q} U_{t}-q E_{t}
$$

Persamaan di atas merupakan persamaan regresi dengan variabel terikat atau tidak bebas (dependent) adalah tingkat perubahan biomassa dan variabel tidak terikat atau bebas (independent) adalah CPUE dan upaya tangkap (effort) (Walter dan Hilborn 1992). Secara umum bentuk regresi model surplus produksi Walter dan Hilborn dapat ditulis sebagai berikut :

$$
\mathrm{Y}=\alpha+\mathrm{BX}_{1 \mathrm{t}}+\gamma \mathrm{X}_{2 \mathrm{t}}+\varepsilon \mathrm{t}
$$


dimana

$$
\begin{aligned}
& \quad Y t=\frac{U_{t+1}}{U_{t}}-1 \\
& \mathrm{X}_{1 \mathrm{t}}=U_{t} \\
& \mathrm{X}_{2 \mathrm{t}}=E_{t} \\
& \varepsilon \mathrm{t}=\text { error-term }
\end{aligned}
$$

Persamaan ini dapat digunakan untuk mengestimasi parameter biologi $r$, $\mathrm{K}$, dan $\mathrm{q}$ secara terpisah dari tiga koefisien persamaan regresi.

Untuk jumlah hasil tangkapan (catch, C), upaya penangkapan (trip/alat tangkap, e), hasil tangkapan per trip alat tangkap, upaya penangkapan (CPUE), dan potensi lestari (Pe) pada kondisi keseimbangan diduga dengan menggunakan persamaan berikut :

$$
\begin{gathered}
C_{M S Y}=\frac{1}{4} * r * \mathrm{k} \\
e_{o p t}=\frac{r}{2 * q} \\
P_{e}=\frac{k}{2} \\
U_{e}=\frac{q * k}{2}
\end{gathered}
$$

Untuk menghitung tingkat pemanfaatan sumberdaya ikan Teri menggunakan Rumus (Sirait et., al 2016), sebagai berikut :

$$
\mathrm{TPc}=\frac{C_{i}}{C M S Y} \times 100 \%
$$

Keterangan :

TPc = Tingkat pemanfaatan pada tahun ke-i (\%)
$\mathrm{Ci}=$ Hasil tangkapan ikan pada

tahun ke-i (kg)

MSY = Maximum Sustainable Yield

$(\mathrm{kg})$

\section{III.HASIL DAN PEMBAHASAN}

Ikan Teri termasuk ikan pelagis ikan pelagis memang merupakan ikan yang biasanya berkelompok (schooling fish) sehingga ketika tertangkap biasanya dalam jumlah yang banyak. Nelayan di perairan Selat Lalang sebagian besar merupakan nelayan skala kecil dan jenis alat tangkap yang digunakan masih tergolong sederhana yaitu Gombang.

Berdasarkan data dari Dinas Perikanan dan Peternakan Kabupaten Siak tahun 2012-2020, alat tangkap yang digunakan untuk menangkap ikan Teri adalah Gombang (Tabel 1). Hasil tangkapan perikanan teri di perairan Selat Lalang dari tahun ke tahun relatif meningkat. Data hasil tangkapan selama tahun 2012-2020, disajikan pada Tabel 1.

CPUE menggambarkan tingkatan nilai produktivitas alat tangkap yang digunakan. Apabila CPUE mengalami penurunan artinya hasil tangkapan rendah, namun upaya penangkapan relatif tinggi. (Arief, 2016). Pada tabel 1, CPUE ikan Teri mengalami fluktuasi. 
Tabel 1. Hubungan Hubungan antara produksi ikan (ton) terhadap Jumlah Upaya (unit) Gombang Periode Tahun 2012 - 2020

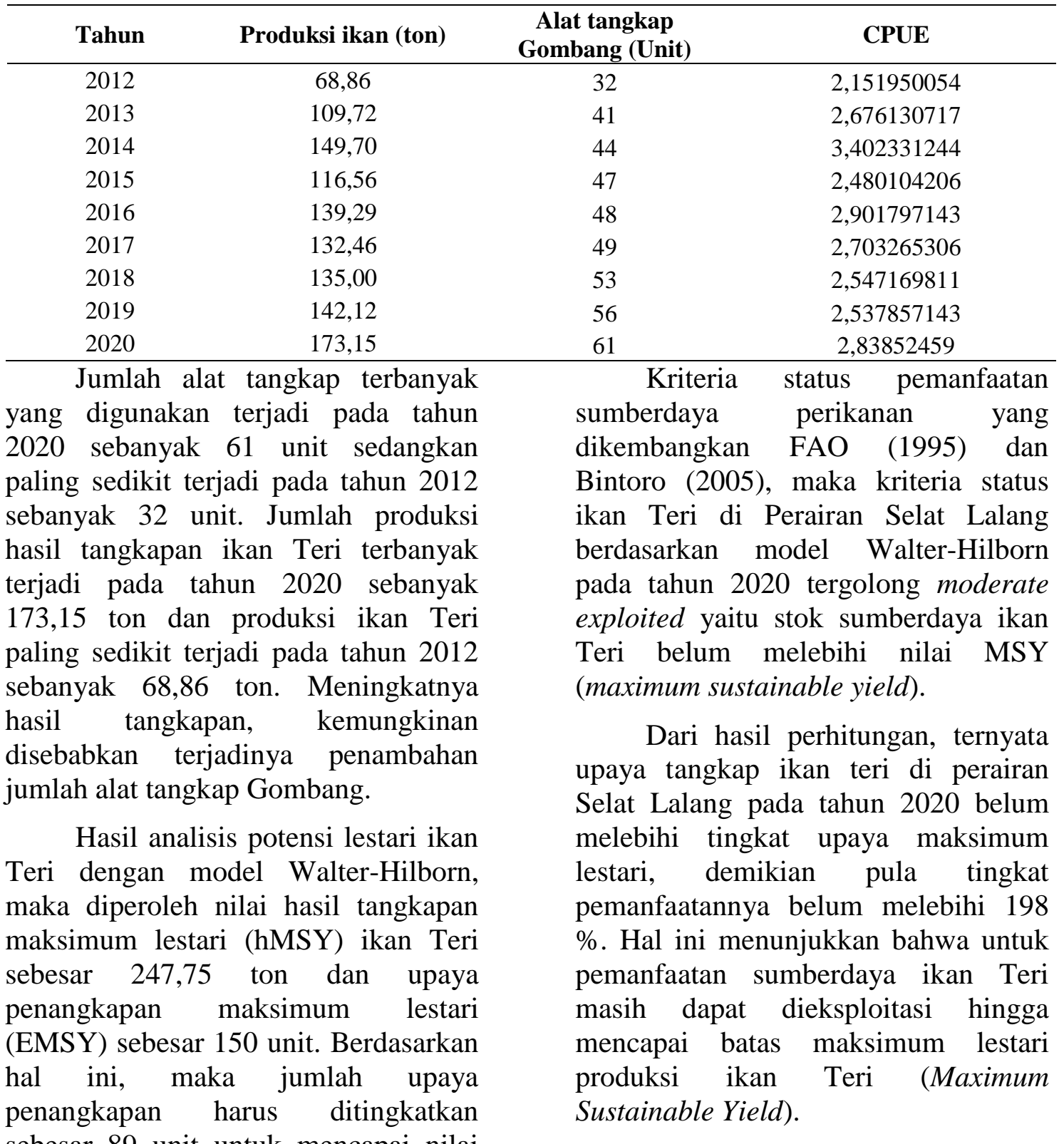
sebesar 89 unit untuk mencapai nilai maximum sustainable yield di Perairan Selat Lalang. Tingkat Pemanfaatan (TP) ikan Teri selama 9 tahun terakhir belum melebihi tingkat pemanfaatan yang diperbolehkan (JTB) yakni dalam kondisi moderate exploited. Tingkat Pemanfaatan (TP) ikan Teri belum melebihi $198 \%$ dari JTB, sedangkan Tingkat pemanfaatan ikan Teri sebesar $73 \%$.

\section{IV.PENUTUP \\ 4.1. Kesimpulan}

Status pemanfaatan ikan Teri di perairan Selat Lalang Selat Lalang berada dalam status moderately exploited. Untuk mendapatkan produksi ikan Teri yang optimal dan berkelanjutan, maka jumlah upaya penangkapan perlu ditingkatkan 
dengan menambahkan jumlah unit alat tangkap.

\subsection{Saran}

Karena ada indikasi terjadinya Underfishing dan besarnya intensitas upaya penangkapan teri di Perairan Selat Lalang, disarankan untuk menambah upaya penangkapan.

\section{DAFTAR PUSTAKA}

Arief, H. 2016. Analisis Bioekonomi (Maximum Sustainable Yield dan Maximum Economic Yield) Multi Spesies Perikanan Laut di PPI Kota Dumai Provinsi Riau. Berkala Perikanan Terubuk, Vol 44. No.1, 111-122.

Beattie A, Sumaila UR, Christensen V, Pauly D. 2002. A model for the bioeconomic evaluation of marine protected area size and placement in the North Sea. Natural Resource Modeling 15: 4.

Bintoro, G. 2005. Pemanfaatan Berkelanjutan Sumberdaya Ikan Tembang (Sardinella fimbriata
Valenciennes, 1847) di Selat Madura Jawa Timur. Institut Pertanian Bogor : Disertasi. Bogor.

Dinas Perikanan dan Peternakan Provinsi Riau. 2021. Statistik Perikanan Tangkap Kabupaten Siak Tahun 2019 